\title{
Author Correction: Stepping to the exit
}

\section{Christiaan M. de Bloeme, Robin W. Jansen, Mark R. L. Krul and Ernst-Jan Geutjes}

Correction to: Nature Biotechnology https://doi.org/10.1038/s41587-021-01007-1, published online 30 August 2021.

In the version of this article initially published, there were errors in the numbers shown in Table 1 and Fig. 3. Specifically, in Table 1, second column, third row, the Preclinical, Total, Phase success rate (\%), the entry now reading " 35 " initially appeared as $45 \%$. In the Fig. 3a "Deals per series" graphic, in the slice corresponding to Series D+, the amount shown was clarified to read “\$77 M." In Fig. 3a caption, the text now reading "a, 1,050 venture financing rounds" initially read 1,051. These changes have been made to the online version of the paper.

Published online: 5 November 2021

https://doi.org/10.1038/s41587-021-01142-9

(c) Springer Nature America, Inc. 20212021

\section{Publisher Correction: Drug hunters uncloak the non-coding 'hidden' genome}

\section{Michael Eisenstein}

Correction to: Nature Biotechnology https://doi.org/10.1038/s41587-021-01088-y, published online 7 October 2021.

In the version of this article initially published, there was an error in the description of Omega's engineered proteins, found in the 16th paragraph, first sentence. In the sentence now reading "Once an IGD and the genes it houses have been associated with a disorder, Omega researchers generate what they call 'Omega Epigenomic Controllers (OECs)," the term "EpiZips" has been replaced by "Omega Epigenomic Controllers (OECs)." Similarly, in the third sentence of the same paragraph, "OECs" replaced "EpiZip" in the sentence now reading "To deliver the treatment, the researchers encapsulate mRNA transcripts within lipid nanoparticles; the mRNA is translated into the OECs after being taken up by the targeted cells."

The errors have been corrected in the online version of the article.

Published online: 11 November 2021

https://doi.org/10.1038/s41587-021-01141-w

(c) The Author(s), under exclusive licence to Springer Nature America, Inc. 20212021

\section{Publisher Correction: Roche deal with RNA-editing spinout}

Correction to: Nature Biotechnology https://doi.org/10.1038/s41587-021-01097-x, published online 7 October 2021.

In the version of this article initially published, there was an error in the second sentence of text. The sentence originally described Shape Therapeutics as a two-year old company; in fact, Shape Therapeutics is three years old. The description has been amended in the online version of the article.

Published online: 26 October 2021

https://doi.org/10.1038/s41587-021-01135-8

(c) Springer Nature America, Inc. 2021 